\title{
Clinical Course of Patients with Intestinal Behçet's Disease According to Consensus-Based Diagnostic Categories
}

\author{
Yu Young Joo' ${ }^{1}$ Bo-In Lee ${ }^{1,2}$, Seung-Jun Kim¹, Han Hee Lee ${ }^{3}$, Jin Su Kim4, Jae Myung Park ${ }^{1,2}$, Young-Seok Cho ${ }^{1,2}$, \\ Kang Moon Lee ${ }^{5}$, Sang Woo Kim ${ }^{6}$, Hwang $\mathrm{Choi}^{7}$, and Myung-Gyu Choi ${ }^{1,2}$ \\ ${ }^{1}$ Division of Gastroenterology, Department of Internal Medicine, Seoul St. Mary's Hospital, College of Medicine, The Catholic \\ University of Korea, ${ }^{2}$ Catholic Photomedicine Research Institute, College of Medicine, The Catholic University of Korea, ${ }^{3}$ Division \\ of Gastroenterology, Department of Internal Medicine, Yeouido St. Mary's Hospital, College of Medicine, The Catholic University \\ of Korea, ${ }^{4}$ Division of Gastroenterology, Department of Internal Medicine, Eunpyeong St. Mary's Hospital, College of Medicine, \\ The Catholic University of Korea, ${ }^{5}$ Division of Gastroenterology, Department of Internal Medicine, St. Vincent's Hospital, College of \\ Medicine, The Catholic University of Korea, ${ }^{6}$ Division of Gastroenterology, Department of Internal Medicine, Uijeongbu St. Mary's \\ Hospital, College of Medicine, The Catholic University of Korea, and 'Division of Gastroenterology, Department of Internal Medicine, \\ Incheon St. Mary's Hospital, College of Medicine, The Catholic University of Korea, Seoul, Korea
}

\section{Article Info}

Received July 7, 2021

Revised September 23, 2021

Accepted September 24, 2021

Published online December 17, 2021

\section{Corresponding Author}

Bo-In Lee

ORCID https://orcid.org/0000-0002-0218-4136

E-mail gidoc4u@gmail.com

\begin{abstract}
Background/Aims: There have been few studies regarding the prognosis of intestinal Behçet's disease ( $\mathrm{BBD}$ ) patients according to consensus-based diagnostic categories, which reflects the typicality of intestinal ulcers, the presence of oral ulcers, and the accompanying systemic manifestations.

Methods: The medical records of patients who had ileocolonic ulcers with a clinical impression of $\mathrm{iBD}$ were reviewed. The patients were categorized according to the diagnostic algorithm at the time of diagnosis. Adverse events were defined as major surgery or admission related to iBD deterioration.

Results: A total of 163 patients were included in the study. The male-to-female ratio was 1:1.2, and the mean age at the time of diagnosis was $48.9 \pm 15.9$ years. The numbers of patients who met the definite, probable, suspected, and nondiagnostic iBD criteria were $19(11.7 \%), 61(37.4 \%)$, $38(23.3 \%)$, and $45(27.6 \%)$, respectively. The event-free survival of patients with definite, probable, and suspected iBD was significantly shorter than that of patients with nondiagnostic iBD $(p=0.026)$, while there was no significant difference among the definite $i B D$, probable $i B D$, and suspected iBD groups $(p=0.596)$. After excluding patients with nondiagnostic $i B D$, multivariate analysis showed that anemia, fever, colonic involvement other than the ileocecum, and accompanying hematologic disorders at the time of diagnosis were significantly associated with the development of adverse events.

Conclusions: The clinical course of patients with definite, probable, and suspected iBD is distinguished from that of patients with nondiagnostic iBD, but patients with definite, probable, and suspected iBD share similar clinical courses. (Gut Liver 2022;16:746-753)
\end{abstract}

Key Words: Behçet syndrome; Inflammatory bowel disease; Prognosis

\section{INTRODUCTION}

Behçet's disease is a chronic, idiopathic, relapsing, and immune-related disease involving multiple organs. It is characterized by recurrent oral ulcers, skin lesions, genital ulcers, ocular inflammation, gastrointestinal ulcers, and vascular lesions. The incidence of Behçet's disease is rare and higher in the Mediterranean area and East Asia than in Western countries. ${ }^{1}$

Approximately $3 \%$ to $16 \%$ of patients with Behçet's disease have gastrointestinal involvement and the ileocecal area is the most common location. ${ }^{2,3}$ The diagnosis of intestinal Behçet's disease (iBD) can be considered when a typical oval-shaped large ulcer in the terminal ileum is 
present, or ulcerations in the small or large intestine are present with clinical findings of Behçet's disease. ${ }^{4}$

The diagnosis of $\mathrm{iBD}$ is often challenging because of manifestations similar to Crohn's disease or intestinal tuberculosis, infrequent pathologic evidence of vasculitis, and the absence of specific laboratory markers for iBD. Moreover, a considerable number of patients with iBD do not present with systemic manifestations when intestinal ulcers are detected. ${ }^{5}$ Therefore, the consensus-based diagnostic criteria for iBD were proposed to reflect the morphology of intestinal ulcers and temporal changes in systemic symptoms. The diagnostic algorithm categorizes patients into four groups of definite, probable, suspected, and nondiagnostic according to the typicality of intestinal ulcers, presence of oral ulcers, and systemic manifestations. The diagnostic accuracy of the first three categories for iBD was proved as $91 \%$.

However, few studies have been performed to analyze the prognosis of $\mathrm{iBD}$ according to the diagnostic categories. This study was performed to evaluate the prognosis of patients with iBD according to their diagnostic categories and the relevant clinical factors affecting the prognosis.

\section{MATERIALS AND METHODS}

\section{Patients}

We reviewed the medical records and colonoscopic findings of patients who had ileocolonic ulcers and a clinical impression of iBD between March 1986 and August 2019 at Seoul St. Mary's Hospital, the Catholic University of Korea, Seoul, Korea. Patients who had undergone previous intestinal resection or were not followed up at least twice after the colonoscopy were excluded. The patients who were finally diagnosed with intestinal tuberculosis, Crohn's disease, ulcerative colitis, infectious colitis, nonsteroidal anti-inflammatory disease-induced enteropathy, or malignant disorders during the follow-up period were also excluded. The study was approved by the Institutional Review Board of Seoul St. Mary's Hospital (IRB number: KC20WISI0232). The waiver of informed consent was approved.

\section{Evaluation and definition of clinical variables}

We collected the baseline demographics, gastrointestinal symptoms, and systemic manifestations at the time of diagnosis and during the follow-up period. Laboratory findings including hemoglobin, serum C-reactive protein, and albumin levels were also included. All the variables for analysis of prognostic factors were selected as those within 30 days of diagnosis.
Disease activity was assessed using the disease activity index for iBD. ${ }^{8}$ All patients underwent a colonoscopy at the time of diagnosis. The shape, location, and typicality of the intestinal ulcers were also reviewed.

\section{Categorization of the patients according to the diagnostic criteria of IBD}

The diagnostic criteria followed the consensus-based diagnostic algorithm by the Korean Inflammatory Bowel Disease Study Group. ${ }^{6}$ The ileocolonic ulcers were classified into "typical" and "atypical" according to the colonoscopic findings. Typical ulcers were defined as round or oval-shaped deep ulcers with discrete borders, which were located at the ileocecal areas and fewer than five in number during the colonoscopic examination. Ulcers that did not fulfill the above characteristics were classified as atypical. The extraintestinal manifestations were defined as the clinical findings by the Behçet's Disease Research Committee of Japan. ${ }^{9}$

Patients with typical ulcers and extraintestinal manifestations were categorized into the definite iBD group. Patients with typical ulcers and recurrent oral ulcers only or those with atypical ulcers and extraintestinal manifestations were assigned to the probable iBD group. Patients with typical ulcers without any extraintestinal manifestations or those with atypical ulcers and recurrent oral ulcers were classified into the suspected iBD group. Patients with atypical ulcers without any extraintestinal manifestations were included in the nondiagnostic iBD group (Fig. 1).

\section{Clinical outcomes}

The primary outcome of the study was event-free survival (EFS). An event was defined as major surgery such as intestinal resection or admission to manage severe intestinal symptoms, bleeding, or complications such as a fistula, abscess, or perforation. The secondary outcome of the study was disease-specific survival (DSS) which was the period from the time of diagnosis to the time of death due to iBD deterioration.

\section{Statistical analysis}

The results were analyzed using analysis of variance, Jonckheere trend test, the linear-by-linear association test, and the chi-square test, as appropriate. The data were expressed as the mean \pm standard deviation. EFS and DSS of the patients were calculated using the Kaplan-Meier analysis and compared by the log-rank test. Univariate and multivariate analyses with the Cox proportional hazard model were used to identify the risk factors for adverse events and disease-specific death. A p-value of less than 0.05 was considered to be statistically significant. Statistical analyses 


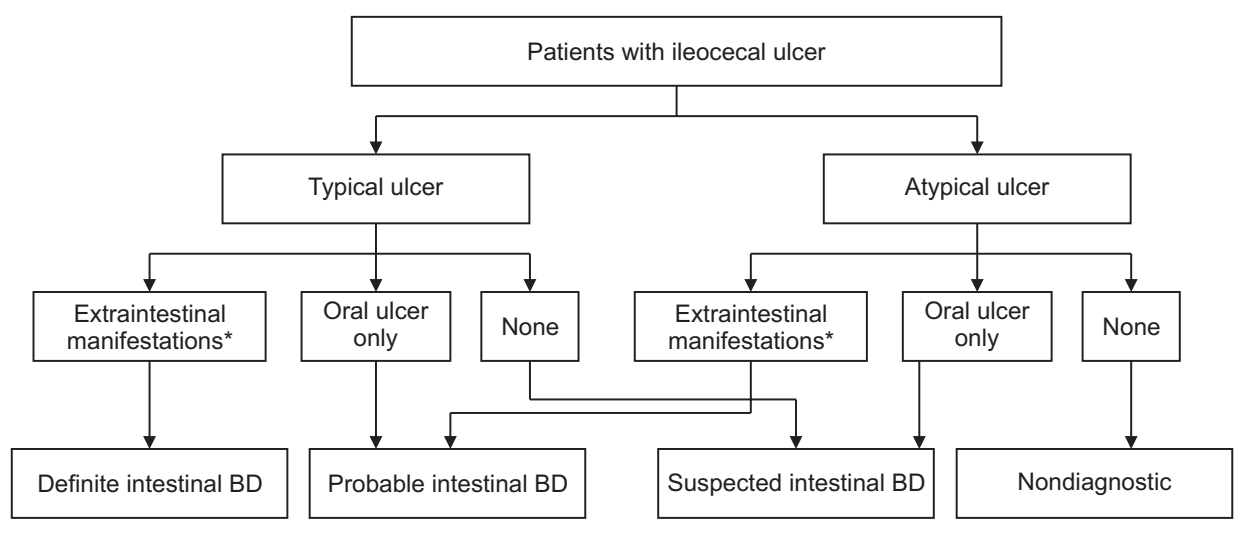

Fig. 1. Diagnostic algorithm for intestinal Behçet's disease (BD). *Extraintestinal manifestations were defined according to the diagnostic criteria of the Behçet's disease Research Committee of Japan. Adapted from Cheon JH, et al. Intest Res 2017;15:311-317. were performed using SAS 9.4 for Windows (SAS Institute, Cary, NC, USA).

\section{RESULTS}

\section{Patient characteristics}

During the study period, a total of 82,704 patients had undergone colonoscopy in our institution. We selected 202 patients who had ileocolonic ulcers and a clinical impression of $\mathrm{iBD}$ at the time of the initial colonoscopy. Among them, 28 patients were excluded because the etiology of their ileocolonic ulcers was proven to be other disorders such as intestinal tuberculosis $(n=3)$, gut graft-versus-host disease $(\mathrm{n}=1)$, and asymptomatic isolated terminal ileal ulcerations $(n=24) .{ }^{10}$ Eleven patients were excluded because of insufficient follow-up (Fig. 2).

Finally, a total of 163 patients were included in the study. Eighty-nine patients (54.6\%) were female and the mean age at the time of diagnosis was $48.9 \pm 15.9$ years. The number of patients with definite, probable, suspected, and nondiagnostic $\mathrm{iBD}$ at the time of diagnosis was 19 (11.7\%), 61 (37.4\%), 38 (23.3\%), and 45 (27.6\%), respectively (Table $1)$.

There were no significant differences in age, sex, hemoglobin, C-reactive protein, and albumin levels at the time of diagnosis between the diagnostic categories. However, the disease activity index for iBD score at the time of diagnosis was significantly different according to the diagnostic categories $(p<0.001)$ and the Jonckheere trend test showed that the score was gradually decreased in the order of definite, probable, suspected, and nondiagnostic iBD $(\mathrm{p}<0.001)$. There were also significant differences in the use of steroids, 5-aminosalicylic acid, immunomodulators, and biologics during the follow-up period according to the diagnostic categories.

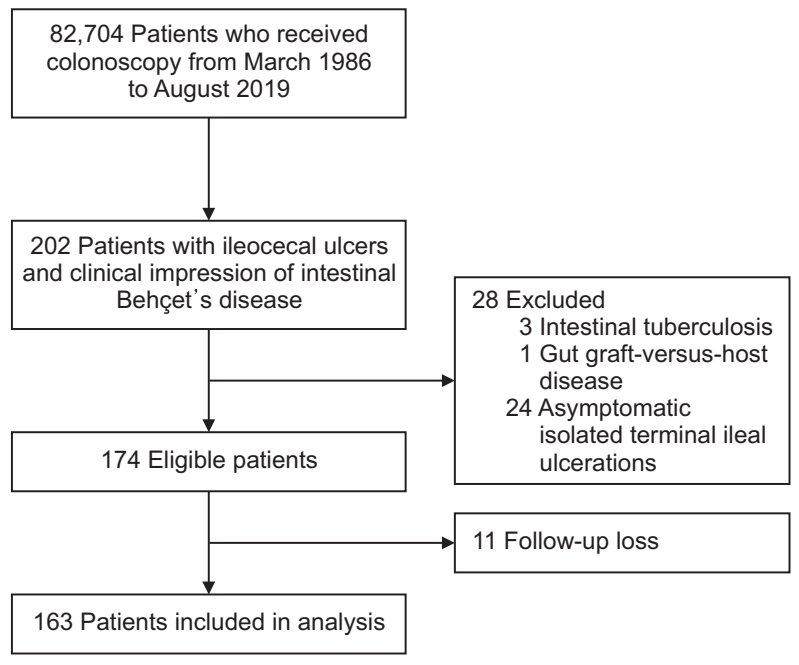

Fig. 2. The study flow diagram.

\section{EFS according to disease categories and prognostic factors at the time of diagnosis}

Among the total of 118 patients with definite, probable, and suspected iBD, 31 patients (26.2\%) were admitted due to iBD-related surgery, severe intestinal symptoms, bleeding, or other complications during the mean follow-up period of $45.0 \pm 58.0$ months. Six of 19 patients with definite iBD (31.6\%) were admitted because of severe intestinal symptoms $(n=3)$ or gastrointestinal bleeding $(n=3)$. None of patients with definite iBD received iBD-related major surgery during the follow-up period. Sixteen of 61 patients with probable iBD (26.2\%) were admitted due to severe symptoms $(n=6)$, perforation $(n=6)$ or gastrointestinal bleeding $(n=4)$. All the six patients who underwent surgery were due to perforation. Nine of 39 patients with suspected iBD (23.7\%) were admitted because of severe symptoms $(n=3)$, ileus $(n=1)$, perforation $(n=2)$, and bleeding $(n=3)$. Among them, three patients with perforation or ileus received surgery (Table 1).

There was no significant difference in EFS between 
Table 1. Baseline Characteristics

\begin{tabular}{|c|c|c|c|c|c|}
\hline Characteristics & $\begin{array}{l}\text { Definite iBD } \\
\quad(n=19)\end{array}$ & $\begin{array}{l}\text { Probable iBD } \\
\qquad(n=61)\end{array}$ & $\begin{array}{l}\text { Suspected iBD } \\
\qquad(n=38)\end{array}$ & $\begin{array}{l}\text { Nondiagnostic } \\
\qquad(n=45)\end{array}$ & $p$-value \\
\hline Age, yr & $44.7 \pm 14.9$ & $46.6 \pm 15.0$ & $49.1 \pm 16.5$ & $53.7 \pm 16.0$ & 0.082 \\
\hline Sex, M:F & $9: 10$ & $25: 36$ & $16: 22$ & $24: 21$ & 0.389 \\
\hline Hemoglobin, g/dL & $12.0 \pm 1.9$ & $12.1 \pm 2.5$ & $12.0 \pm 2.6$ & $13.3 \pm 2.2$ & 0.040 \\
\hline $\mathrm{CRP}, \mathrm{mg} / \mathrm{dL}$ & $1.1(0.6-5.6)$ & $1.1(0.3-3.7)$ & $1.2(0.1-3.3)$ & $0.2(0.1-1.0)$ & $0.010^{*}$ \\
\hline Albumin, g/dL & $3.9 \pm 0.5$ & $3.9 \pm 0.6$ & $3.9 \pm 0.6$ & $4.1 \pm 0.5$ & 0.466 \\
\hline DAIBD score & $60.3 \pm 29.1$ & $60.2 \pm 29.2$ & $49.1 \pm 30.7$ & $22.2 \pm 19.4$ & $<0.001$ \\
\hline \multicolumn{6}{|l|}{ Treatment } \\
\hline Steroid & $18(94.7)$ & $44(72.1)$ & $17(44.7)$ & $2(4.4)$ & $<0.001$ \\
\hline $5-A S A$ & 16 (84.2) & $37(60.7)$ & 25 (65.8) & $1(2.2)$ & $<0.001$ \\
\hline Immunomodulator & 3 (15.8) & $11(18.3)$ & $1(2.6)$ & $1(2.2)$ & 0.005 \\
\hline Biologics & $9(47.4)$ & $12(20.0)$ & $5(13.2)$ & 0 & $<0.001$ \\
\hline Thalidomide & 0 & $1(1.7)$ & 0 & 0 & \\
\hline Oral ulcers & $19(100)$ & $60(98.4)$ & 34 (89.5) & 0 & $<0.001$ \\
\hline \multicolumn{6}{|l|}{ Systemic Behçet symptoms } \\
\hline Genital ulcers & 12 (63.2) & $28(46.0)$ & 0 & 0 & $<0.001$ \\
\hline Uveitis & $6(31.6)$ & 9 (14.8) & 0 & 0 & $<0.001$ \\
\hline Skin lesion & $8(42.1)$ & $14(23.0)$ & 0 & 0 & $<0.001$ \\
\hline Colonic involvement other than ileocecal area & $2(10.5)$ & $16(26.2)$ & $11(28.9)$ & $8(17.8)$ & 0.739 \\
\hline Adverse event & $6(31.6)$ & $16(26.2)$ & $12(31.6)$ & 0 & \\
\hline Operation & 0 & 6 (9.8) & $3(7.9)$ & 0 & \\
\hline Admission & $6(31.6)$ & $10(16.4)$ & $9(23.7)$ & 0 & \\
\hline Hematologic disorder & $2(10.5)$ & $10(16.4)$ & $8(21.1)$ & $1(2.2)$ & \\
\hline MDS & $1(5.3)$ & $4(6.6)$ & $4(10.5)$ & 0 & \\
\hline AA & 0 & $5(8.2)$ & $1(2.6)$ & $1(2.2)$ & \\
\hline $\mathrm{AML}$ & 0 & 0 & $1(2.6)$ & 0 & \\
\hline Lymphoma & 1 (5.3) & 0 & $1(2.6)$ & 0 & \\
\hline Multiple myeloma & 0 & $1(1.7)$ & 0 & 0 & \\
\hline ITP & 0 & 0 & $1(2.6)$ & 0 & \\
\hline Follow-up, mo & $65.6 \pm 64.7$ & $54.5 \pm 71.5$ & $47.0 \pm 51.2$ & $24.3 \pm 27.4$ & \\
\hline iBD-related admission & $6(31.6)$ & $16(26.2)$ & 9 (23.7) & 0 & \\
\hline iBD-related surgery & 0 & 6 (9.8) & $3(10.5)$ & 0 & \\
\hline iBD-related death & $1(5.3)$ & 2 (3.3) & $2(5.3)$ & 0 & \\
\hline
\end{tabular}

Data are presented as mean $\pm \mathrm{SD}$, median (interquartile range), or number (\%).

iBD, intestinal Behçet's disease; M, male; F, female; CRP, C-reactive protein; DAIBD, disease activity index for intestinal Behçet's disease; 5-ASA, 5-aminosalicylic acid; MDS, myelodysplastic syndrome; AA, aplastic anemia; AML, acute myeloid leukemia; ITP, idiopathic thrombocytopenic purpura.

*Kruskal-Wallis test.

the definite, probable, suspected, and nondiagnostic iBD groups ( $\mathrm{p}=0.087$ ). When the definite, probable, and suspected groups were included in the diagnostic $\mathrm{BBD}$ group, there was a significant difference in EFS between the diagnostic iBD group and the nondiagnostic iBD group $(\mathrm{p}=0.021)$ (Fig. 3).

Univariate analysis showed that a hemoglobin level of $<10.0 \mathrm{~g} / \mathrm{dL}$, serum albumin of $<3.0 \mathrm{~g} / \mathrm{dL}$, fever $\geq 38.0^{\circ} \mathrm{C}$, colonic involvement other than the ileocecal area, and accompanying hematologic disorders at the time of diagnosis were associated with the development of adverse events (Table 2). In multivariate analysis, a hemoglobin level of $<10.0 \mathrm{~g} / \mathrm{dL}$, fever $\geq 38.0^{\circ} \mathrm{C}$, colonic involvement other than the ileocecal area, and accompanying hematologic disorders at the time of diagnosis were significant factors for de- velopment of adverse events (hazard ratio [HR], 4.01; 95\% confidence interval [CI], 1.67 to 9.60; HR, 2.54; 95\% CI, 1.10 to 5.89 ; HR, $4.19,95 \%$ CI, 1.77 to 9.92 ; HR, 2.91 ; $95 \%$ CI, 1.18 to 7.13 , respectively).

\section{DSS according to disease categories and prognostic factors at the time of diagnosis}

Among the 118 patients with definite, probable, and suspected $\mathrm{iBD}$, nine patients (7.6\%) died during the followup period. Among them, five deaths $(4.3 \%)$ were associated with iBD progression, and the other four patients expired from lung cancer $(\mathrm{n}=2)$ and cerebral hemorrhage $(\mathrm{n}=2)$.

There was no significant difference in DSS between the definite, probable, suspected, and nondiagnostic iBD 
A

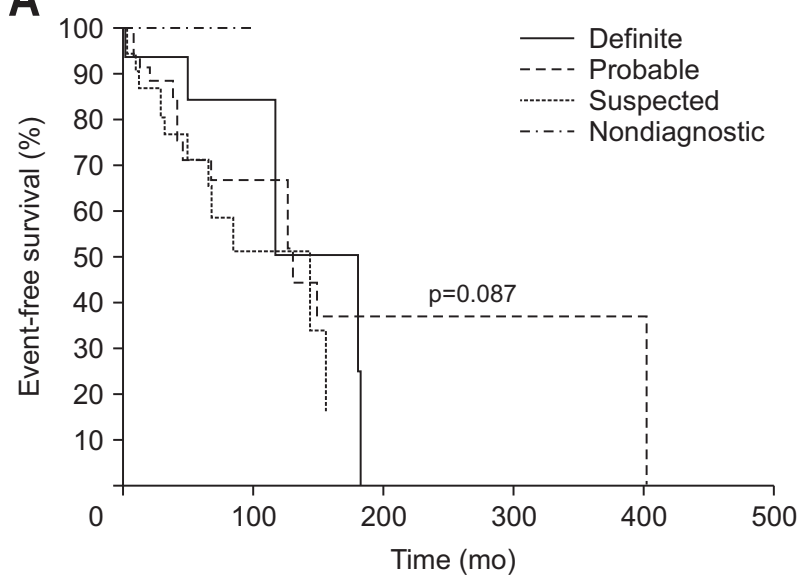

B

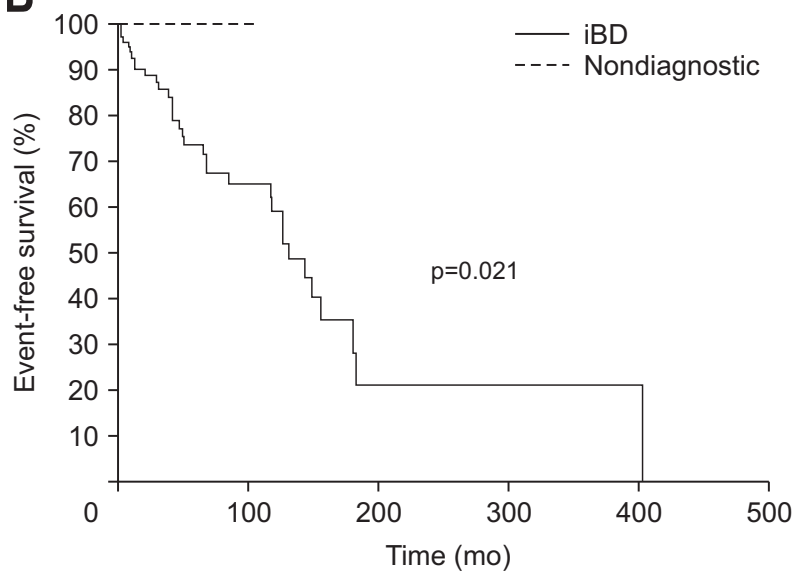

Fig. 3. Event-free survival (EFS) according to the diagnostic categories. (A) EFS of the definite, probable, suspected, and nondiagnostic intestinal Behçet's disease (iBD) groups. (B) EFS of diagnostic iBD (definite+probable+suspected iBD) and nondiagnostic iBD.

Table 2. Analysis of Prognostic Factors of Intestinal Behçet's Disease for the Development of Adverse Events

\begin{tabular}{|c|c|c|c|c|c|c|c|}
\hline \multirow{2}{*}{ Characteristics } & \multirow{2}{*}{ Category } & \multicolumn{3}{|c|}{ Univariate analysis } & \multicolumn{3}{|c|}{ Multivariate analysis } \\
\hline & & $\mathrm{HR}$ & $95 \% \mathrm{Cl}$ & $p$-value & HR & $95 \% \mathrm{Cl}$ & $\mathrm{p}$-value \\
\hline Age & $\begin{array}{l}\geq 40 \mathrm{yr} \\
<40 \mathrm{yr}\end{array}$ & 1.67 & $0.79-3.56$ & 0.182 & & & \\
\hline Sex & $\begin{array}{l}\text { Male } \\
\text { Female }\end{array}$ & 1.18 & $0.58-2.39$ & 0.655 & & & \\
\hline Typicality of ulcer & $\begin{array}{l}\text { Typical } \\
\text { Atypical }\end{array}$ & 1.10 & $0.54-2.19$ & 0.804 & & & \\
\hline Histology-proven vasculitis & $\begin{array}{l}\text { Yes } \\
\text { No }\end{array}$ & 1.50 & $0.51-4.40$ & 0.924 & & & \\
\hline $\begin{array}{l}\text { Systemic Behçet's disease } \\
\text { symptoms }\end{array}$ & $\begin{array}{l}\text { Yes } \\
\text { No }\end{array}$ & 1.33 & $0.18-9.91$ & 0.780 & & & \\
\hline Abdominal pain & $\begin{array}{l}\text { Yes } \\
\text { No }\end{array}$ & 1.58 & $0.73-3.44$ & 0.245 & & & \\
\hline Hemoglobin & $\begin{array}{l}<10.0 \mathrm{~g} / \mathrm{dL} \\
\geq 10.0 \mathrm{~g} / \mathrm{dL}\end{array}$ & 4.53 & $2.16-9.50$ & $<0.001$ & 4.01 & $1.67-9.60$ & 0.002 \\
\hline C-reactive protein & $\begin{array}{l}\geq 2.5 \mathrm{mg} / \mathrm{dL} \\
<2.5 \mathrm{mg} / \mathrm{dL}\end{array}$ & 1.89 & $0.92-3.87$ & 0.082 & & & \\
\hline Albumin & $\begin{array}{l}<3.0 \mathrm{~g} / \mathrm{dL} \\
\geq 3.0 \mathrm{~g} / \mathrm{dL}\end{array}$ & 10.65 & $3.16-35.90$ & $<0.001$ & 2.17 & $0.57-8.21$ & 0.253 \\
\hline Fever & $\begin{array}{l}\geq 38.0^{\circ} \mathrm{C} \\
<38.0^{\circ} \mathrm{C}\end{array}$ & 2.64 & $1.21-5.74$ & 0.013 & 2.54 & $1.10-5.89$ & 0.030 \\
\hline DAIBD & $\begin{array}{l}\geq 40 \\
<40\end{array}$ & 3.20 & $0.76-13.41$ & 0.112 & & & \\
\hline $\begin{array}{l}\text { Colonic involvement other than } \\
\text { ileocecal area }\end{array}$ & $\begin{array}{l}\text { Yes } \\
\text { No }\end{array}$ & 5.78 & $2.67-12.48$ & $<0.001$ & 4.19 & $1.77-9.92$ & 0.001 \\
\hline Hematologic disorders & $\begin{array}{l}\text { Yes } \\
\text { No }\end{array}$ & 5.54 & $2.30-13.33$ & $<0.001$ & 2.91 & $1.18-7.13$ & 0.019 \\
\hline
\end{tabular}

$\mathrm{HR}$, hazard ratio; $\mathrm{Cl}$, confidence interval; DAIBD, disease activity index for intestinal Behçet's disease.

groups $(\mathrm{p}=0.714)$. There also was no significant difference in DSS between the diagnostic iBD (definite, probable, and suspected $\mathrm{iBD}$ ) and nondiagnostic $\mathrm{iBD}$ group $(\mathrm{p}=0.584)$.

The Cox proportional hazard model revealed that lower hemoglobin levels $(<10.0 \mathrm{~g} / \mathrm{dL})$ at the time of diagnosis were the only significant factor associated with poor DSS in univariate (HR, 6.41; 95\% CI, 1.03 to 40.07$)$ and multivariate analysis (HR, 6.41; 95\% CI, 1.03 to 40.07 ) (Table 3).

\section{Chronological changes in the diagnostic category during the follow-up period}

During the follow-up period, each of the two patients 
Table 3. Analysis of Prognostic Factors of Intestinal Behçet's Disease for Disease-Specific Survival

\begin{tabular}{|c|c|c|c|c|c|c|c|}
\hline \multirow{2}{*}{ Characteristics } & \multirow{2}{*}{ Category } & \multicolumn{3}{|c|}{ Univariate analysis } & \multicolumn{3}{|c|}{ Multivariate analysis } \\
\hline & & $\mathrm{HR}$ & $95 \% \mathrm{Cl}$ & $\mathrm{p}$-value & $\mathrm{HR}$ & $95 \% \mathrm{Cl}$ & p-value \\
\hline Age & $\begin{array}{l}\geq 40 \mathrm{yr} \\
<40 \mathrm{yr}\end{array}$ & 2.45 & $0.27-22.55$ & 0.430 & & & \\
\hline Sex & $\begin{array}{l}\text { Male } \\
\text { Female }\end{array}$ & 1.79 & $0.30-10.72$ & 0.524 & & & \\
\hline Typicality of ulcer & $\begin{array}{l}\text { Typical } \\
\text { Atypical }\end{array}$ & 2.32 & $0.39-13.88$ & 0.359 & & & \\
\hline Histology-proven vasculitis & $\begin{array}{l}\text { Yes } \\
\text { No }\end{array}$ & 4.95 & $0.50-48.70$ & 0.170 & & & \\
\hline $\begin{array}{l}\text { Systemic Behçet's disease } \\
\text { symptoms }\end{array}$ & $\begin{array}{l}\text { Yes } \\
\text { No }\end{array}$ & 20.87 & $0.00-3.498 \mathrm{E}+13$ & 0.832 & & & \\
\hline Abdominal pain & $\begin{array}{l}\text { Yes } \\
\text { No }\end{array}$ & 1.11 & $0.18-6.67$ & 0.911 & & & \\
\hline Hemoglobin & $\begin{array}{l}<10 \mathrm{~g} / \mathrm{dL} \\
\geq 10 \mathrm{~g} / \mathrm{dL}\end{array}$ & 6.41 & $1.03-40.07$ & 0.047 & 6.41 & $1.03-40.07$ & 0.047 \\
\hline C-reactive protein & $\begin{array}{l}\geq 2.5 \mathrm{mg} / \mathrm{dL} \\
<2.5 \mathrm{mg} / \mathrm{dL}\end{array}$ & 1.53 & $0.21-10.87$ & 0.673 & & & \\
\hline Albumin & $\begin{array}{l}<3.0 \mathrm{~g} / \mathrm{dL} \\
\geq 3.0 \mathrm{~g} / \mathrm{dL}\end{array}$ & 21.68 & $0.00-1.260 \mathrm{E}+10$ & 0.765 & & & \\
\hline Fever & $\begin{array}{l}\geq 38.0^{\circ} \mathrm{C} \\
<38.0^{\circ} \mathrm{C}\end{array}$ & 1.98 & $0.22-17.73$ & 0.543 & & & \\
\hline DAIBD & $\begin{array}{l}\geq 40 \\
<40\end{array}$ & 1.12 & $0.12-10.16$ & 0.922 & & & \\
\hline $\begin{array}{l}\text { Colonic involvement other than } \\
\text { ileocecal area }\end{array}$ & $\begin{array}{l}\text { Yes } \\
\text { No }\end{array}$ & 6.15 & $0.98-38.57$ & 0.053 & & & \\
\hline Hematologic disorders & $\begin{array}{l}\text { Yes } \\
\text { No }\end{array}$ & $29,322.19$ & $0.00-2.773 \mathrm{E}+31$ & 0.746 & & & \\
\hline
\end{tabular}

$\mathrm{HR}$, hazard ratio; $\mathrm{Cl}$, confidence interval; DAIBD, disease activity index for intestinal Behçet's disease.

with suspected $\mathrm{iBD}$ at the time of the initial diagnosis became compatible with probable iBD by the development of typical ulcers and uveitis, respectively. One patient with probable iBD became compatible with definite $\mathrm{BBD}$ by the development of typical ulcers (Fig. 4). None of the patients with nondiagnostic iBD changed their diagnostic category during the follow-up period.

\section{DISCUSSION}

Our study showed for the first time that the clinical course of patients with definite, probable, and suspected iBD was clearly distinguished from that of patients with nondiagnostic $\mathrm{iBD}$. In contrast, the clinical course between patients with definite, probable, and suspected iBD was not significantly different, which suggests that the former three categories belong to a single disease entity called iBD.

The diagnostic algorithm of $\mathrm{iBD}$ is mainly dependent upon the typicality of intestinal ulcers, presence of oral ulcers, and accompanying systemic manifestations, and our univariate and multivariate analyses showed that those factors were not significantly associated with the development

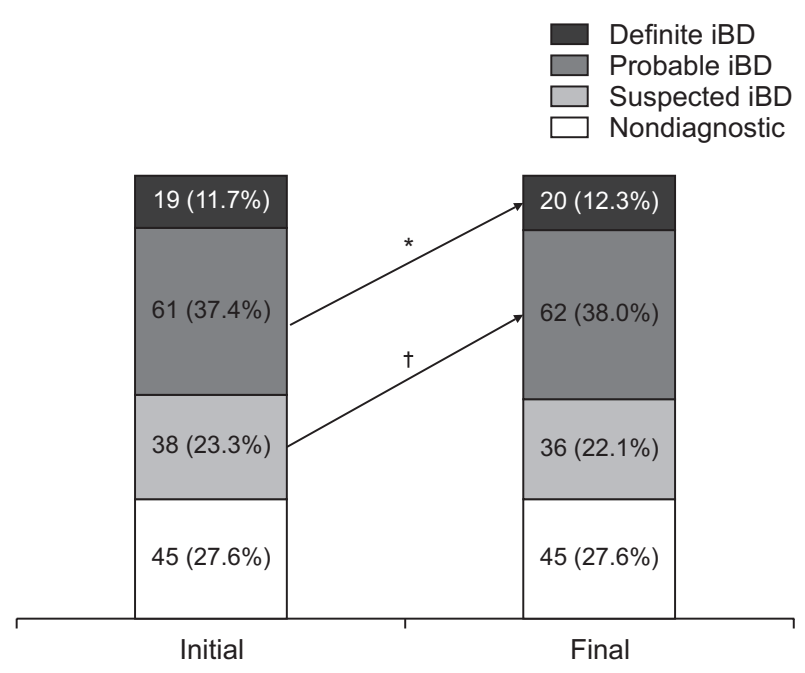

Fig. 4. Chronological changes in the diagnostic categories. ${ }^{*}$ The initial diagnosis of patients with probable intestinal Behçet's disease (iBD) was changed into definite $\mathrm{iBD}$ at the end of the follow-up by the development of typical ulcers; ${ }^{\dagger} T$ The initial diagnosis of two patients with suspected $\mathrm{iBD}$ was changed into probable $\mathrm{iBD}$ at the end of the follow-up by the development of typical ulcers and uveitis, respectively.

of adverse events or poor DSS. A previous retrospective study also did not find any difference in clinical charac- 
teristics between iBD patients who fulfilled the systemic manifestations and those with few systemic manifestations. ${ }^{5}$ These findings are consistent with our results that no significant differences were found in the clinical courses of patients with definite, probable, and suspected iBD.

The diagnostic algorithm was developed because the diagnosis of $\mathrm{iBD}$ using the previous criteria was not easy due to systemic symptoms emerging at different times during the disease course. ${ }^{6}$ Likewise in our study, a total of three patients with probable or suspected $\mathrm{iBD}$ were assigned to higher diagnostic categories due to the development of extraintestinal manifestations during the follow-up period. However, none of the patients with nondiagnostic iBD were diagnosed with definite, probable, or suspected $\mathrm{iBD}$ during the follow-up period, indicating again that the three categories were distinguished as a single disease entity from nondiagnostic iBD.

The disease course of $\mathrm{iBD}$ is frequently unpredictable with relapse and remission and related to adverse outcomes including significant morbidity and mortality. According to a Korean nationwide population-based study, ${ }^{11}$ the cumulative rates of surgery and hospitalization at 1 and 4 years after diagnosis were $11 \%$ and $32 \%$, respectively. In our study, the rates surgery and hospitalization of for patients with definite, probable, and suspected $\mathrm{BBD}$ at 1 and 4 years was $7.3 \%$ and $22.6 \%$, respectively. Anti-tumor necrosis factor agents are proven to be effective for inducing and maintaining the clinical remission of $\mathrm{iBD},{ }^{12-14}$ and proactive management of patients with higher risk in the early stage may decrease disease-specific morbidity and mortality. ${ }^{7}$ Thus, the identification of $\mathrm{iBD}$ with a higher risk in the early stage is very important.

Previous studies reported that younger age at the time of diagnosis, higher initial disease activity, and the presence of volcano-type ulcers were risk factors for surgery. ${ }^{15,16}$ In our study, age under 40 at the time of diagnosis was not associated with a higher risk of major surgery or admission (HR, $0.60 ; 95 \%$ CI, 0.28 to 1.26). The HR of disease activity index for intestinal Behçet's disease score at the time of diagnosis $\geq 40$ was 3.20 ( $95 \%$ CI, 0.76 to 13.41 ) in the univariate analysis, which was not significant. The presence of typical ulcers was also not associated with the development of adverse events.

Our study showed that anemia, fever, colonic involvement other than the ileocecum, and accompanying hematologic disorders at the time of diagnosis were poor prognostic factors of $\mathrm{iBD}$. It is known that Behçet's disease is associated with hematologic disorders, especially bone marrow failure such as myelodysplastic syndrome or aplastic anemia. ${ }^{17-19}$ Patients with Behçet's disease and bone marrow failure showed more frequent intestinal involve- ment and refractoriness to steroids and immunomodulators $^{16}$ and the proportion of trisomy 8 was reported in up to $64 \%-86 \%$ of patients with Behçet's disease and bone marrow failure. ${ }^{20-22}$ In our study, accompanying hematologic disorders at the time of diagnosis were associated with a higher risk of major surgery or admission related to iBD (HR, 2.91; 95\% CI, 1.18 to 7.13). Of the 118 patients with definite, probable, and suspected iBD, hematologic disorders were present in 20 (16.9\%) and there were seven patients with trisomy 8 among the 15 patients with bone marrow failure (46.7\%).

This study had some limitations. First, this was a singlecenter retrospective study based on the review of medical records. However, a relatively large number of patients with $\mathrm{BBD}$ were included and followed up for considerable periods. Second, the mean follow-up period of the patients with nondiagnostic $\mathrm{iBD}$ was shorter. However, we believe that the follow-up of those patients was stopped by their doctors or patients themselves because of minimal clinical symptoms or a favorable clinical course.

In conclusion, our study demonstrated that the clinical course of patients with definite, probable, and suspected $\mathrm{iBD}$ was clearly distinguished from that of the patients with nondiagnostic $\mathrm{iBD}$ and the consensus-based diagnostic algorithm could diagnose patients with $\mathrm{iBD}$ at the early stage of the disease. Patients with definite, probable, and suspected iBD share similar clinical courses, and active treatments should be considered regardless of their diagnostic subtypes. Anemia, fever, colonic involvement other than the ileocecum, and accompanying hematologic disorders at the time of diagnosis are poor prognostic factors of iBD. Further studies are required to evaluate whether advanced treatment at the early stage can change the clinical course of $i B D$ patients with risk factors.

\section{CONFLICTS OF INTEREST}

No potential conflict of interest relevant to this article was reported.

\section{AUTHOR CONTRIBUTIONS}

Conceptualization: B.I.L. Data curation: Y.Y.J. Formal analyses and investigation: Y.Y.J., B.I.L. Resources: S.J.K., H.H.L., J.S.K., J.M.P., Y.S.C., K.M.L., S.W.K., H.C., M.G.C. Supervision: B.I.L., K.M.L., S.W.K., H.C., M.G.C. Writing original draft: Y.Y.J. Writing - review and editing: B.I.L. All authors read and approved the final manuscript. 


\section{ORCID}

Yu Young Joo

https://orcid.org/0000-0002-0124-7457

Bo-In Lee https://orcid.org/0000-0002-0218-4136

Seung-Jun Kim https://orcid.org/0000-0003-3965-3378

Han Hee Lee https://orcid.org/0000-0002-8244-374X

Jin Su Kim https://orcid.org/0000-0002-3397-3189

Jae Myung Park https://orcid.org/0000-0002-1534-7467

Young-Seok Cho https://orcid.org/0000-0003-1537-3427

Kang Moon Lee https://orcid.org/0000-0003-2850-4553

Sang Woo Kim https://orcid.org/0000-0002-9331-9015

Hwang Choi https://orcid.org/0000-0003-4747-7212

Myung-Gyu Choi https://orcid.org/0000-0003-4083-5187

\section{REFERENCES}

1. Suzuki Kurokawa M, Suzuki N. Behcet's disease. Clin Exp Med 2004;4:10-20.

2. Sakane T, Takeno M, Suzuki N, Inaba G. Behçet's disease. N Engl J Med 1999;341:1284-1291.

3. Hisamatsu T, Ueno F, Matsumoto T, et al. The 2nd edition of consensus statements for the diagnosis and management of intestinal Behçet's disease: indication of anti-TNFa monoclonal antibodies. J Gastroenterol 2014;49:156-162.

4. Kobayashi K, Ueno F, Bito S, et al. Development of consensus statements for the diagnosis and management of intestinal Behçet's disease using a modified Delphi approach. J Gastroenterol 2007;42:737-745.

5. Lee CR, Kim WH, Cho YS, et al. Colonoscopic findings in intestinal Behçet's disease. Inflamm Bowel Dis 2001;7:243249.

6. Cheon JH, Lee HJ. Optimal diagnosis and disease activity monitoring of intestinal Behcet's disease. Intest Res 2017;15:311-317.

7. Cheon JH, Kim WH. An update on the diagnosis, treatment, and prognosis of intestinal Behçet's disease. Curr Opin Rheumatol 2015;27:24-31.

8. Cheon JH, Han DS, Park JY, et al. Development, validation, and responsiveness of a novel disease activity index for intestinal Behçet's disease. Inflamm Bowel Dis 2011;17:605-613.

9. Kurokawa MS, Yoshikawa H, Suzuki N. Behçet's disease. Semin Respir Crit Care Med 2004;25:557-568.

10. Chang HS, Lee D, Kim JC, et al. Isolated terminal ileal ulcerations in asymptomatic individuals: natural course and clinical significance. Gastrointest Endosc 2010;72:1226-1232.

11. Han M, Jung YS, Kim WH, Cheon JH, Park S. Incidence and clinical outcomes of intestinal Behçet's disease in Korea, 2011-2014: a nationwide population-based study. J Gastroenterol 2017;52:920-928.

12. Naganuma M, Sakuraba A, Hisamatsu T, et al. Efficacy of infliximab for induction and maintenance of remission in intestinal Behçet's disease. Inflamm Bowel Dis 2008;14:12591264.

13. Ariyachaipanich A, Berkelhammer C, Nicola H. Intestinal Behçet's disease: maintenance of remission with adalimumab monotherapy. Inflamm Bowel Dis 2009;15:1769-1771.

14. Suzuki Y, Hagiwara T, Kobayashi M, Morita K, Shimamoto T, Hibi T. Is adalimumab safe and effective in patients with intestinal Behcet's disease in real-world practice? Intest Res 2021;19:301-312.

15. Jung YS, Yoon JY, Hong SP, Kim TI, Kim WH, Cheon JH. Influence of age at diagnosis and sex on clinical course and long-term prognosis of intestinal Behcet's disease. Inflamm Bowel Dis 2012;18:1064-1071.

16. Park JJ, Kim WH, Cheon JH. Outcome predictors for intestinal Behçet's disease. Yonsei Med J 2013;54:1084-1090.

17. Ahn JK, Cha HS, Koh EM, et al. Behcet's disease associated with bone marrow failure in Korean patients: clinical characteristics and the association of intestinal ulceration and trisomy 8. Rheumatology (Oxford) 2008;47:1228-1230.

18. Soysal T, Salihoğlu A, Esatoğlu SN, et al. Bone marrow transplantation for Behçet's disease: a case report and systematic review of the literature. Rheumatology (Oxford) 2014;53: 1136-1141.

19. Shen Y, Ma HF, Luo D, Cai JF, Zou J, Guan JL. High incidence of gastrointestinal ulceration and cytogenetic aberration of trisomy 8 as typical features of Behçet's disease associated with myelodysplastic syndrome: a series of 16 consecutive Chinese patients from the Shanghai Behçet's disease database and comparison with the literature. Biomed Res Int 2018;2018:8535091.

20. Tada Y, Koarada S, Haruta Y, Mitamura M, Ohta A, Nagasawa K. The association of Behçet's disease with myelodysplastic syndrome in Japan: a review of the literature. Clin Exp Rheumatol 2006;24(5 Suppl 42):S115-S119.

21. Kawabata H, Sawaki T, Kawanami T, et al. Myelodysplastic syndrome complicated with inflammatory intestinal ulcers: significance of trisomy 8. Intern Med 2006;45:1309-1314.

22. Mori Y, Iwamoto F, Ishida Y, et al. Long-term outcome after surgery in a patient with intestinal Behçet's disease complicated by myelodysplastic syndrome and trisomy 8 . Intest Res 2020;18:469-475. 